\title{
Q\&A: Tom Wolfe on language and the mind
}

Behind the novelist's eye of Tom Wolfe - bestselling author of Bonfire of the Vanities - lies a keen interest in brain science. Discussing the origin of language this week with Steven Pinker at the Brainwave festival in New York, Wolfe explains why he sees human behaviour as more than mechanistic, and genetic theory as little more than literature.

\begin{abstract}
Your father was an agronomist. Did he give you a taste for science?

Actually, no. He worked at the Virginia Agricultural Experiment Station, dealing mainly in corn [maize], whose yield was enormously increased by artificial selection. My father edited a farm magazine called The Southern Planter. I would see him writing on a yellow legal pad and two weeks later his words were converted into beautiful, sharp-edged type. I was five years old, and it seemed magical. I lost track of the science. I just wanted to write.
\end{abstract}

\section{When did you become interested in the brain?}

When I enrolled in the American Studies graduate programme at Yale University I fell in love with sociology. I realized that almost everything one does is determined by status considerations - just think of your conduct in the bathroom, all by yourself. As early as 1956, I became convinced that there must be some area of the brain that determines this drive. I started trying to study brain physiology, only to discover that the status of Sigmund Freud's psychology was so high that the science had practically come to a halt. When it turned out that Freud did not have the answers - a fact brought out by lithium - only then did neuroscience, as we know it, get started.

\section{Where did you begin your study?}

The first thing I found was the book Physical Control of the Mind by the Spanish physician José Delgado at Yale. He was one of the first to insert needles into the brain to show where the seat of certain impulses were. Delgado proved his theory by letting himself be charged by a raging bull into whose brain he had sunk a stereotaxic needle. He pressed a button on a radio transmitter and the bull came to a screeching halt, like in the cartoons. $\mathrm{He}$ is still, to my thinking, the greatest neuroscientist ever.

\section{Why are you sceptical about genetic} explanations for human behaviour? So many neuroscientists have become gnostics - convinced they see things the rest of us can't see because they've had a revelation. They have a secret: what we call

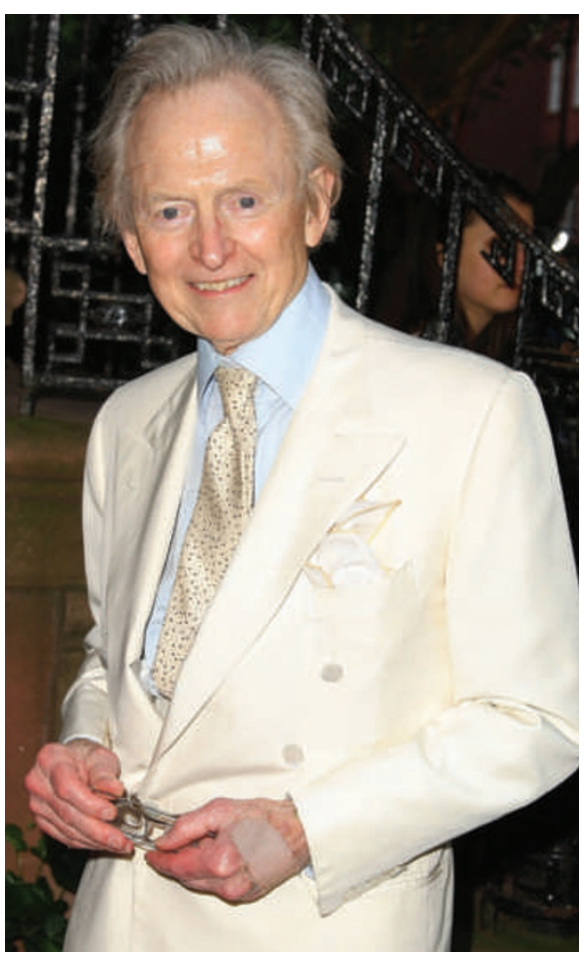

Tom Wolfe's interest in the brain was sparked by the mind-control experiments of José Delgado.

'soul,' 'mind' and even 'self' must go into quotation marks. There's no 'me' inside of me. We are machines programmed at birth; we think we have free choice but we don't. But none of this has any scientific basis. As Delgado's son has said, we are not two miles down the long road of understanding the brain, we are two millimetres, and all the rest is literature.

\section{What is your view of the origins of language?}

It's my contention that evolution stopped when the first caveman spoke. Nobody knows when or how language was invented. Steven Pinker calls it an instinct that grows out of the process of evolution. My view is that language is an artefact like an axe or a sword, which can affect people's behaviour thousands of years later. Right now, as we speak, I'll bet you there are at least 250 million orgasms taking place that would not have taken place had Freud never lived. This is the influence of words. They will not lie down.
A Forbes article you wrote in 1996 made some think you wanted to defend the soul against the onslaught of science.

That is ludicrous. I don't care one way or another about the existence of the soul. I wrote the piece 'Sorry, but your soul just died' to point out that the march of neuroscience and genetic theory was beginning to prove Friedrich Nietzsche's prediction that the twenty-first century would see the eclipse of all values. If you have the gnostic belief that we are all just machines, and we react to one another according to how we are programmed, there is no room for values. I didn't say the theory was wrong. I predicted that, if it was proven correct, it would depress people.

Do you believe such a deterministic view of the brain could be validated?

My view in 1996 was, if they actually do end up proving it, I'd like to be there to report on it. It's all great journalism as far as I'm concerned - that's my sole interest. I now see that I made a mistake in trying to conflate neuroscience, which really is a science, with genetic theory, which is pure literature.

\section{You predicted that, by 2006, brain imaging would be more important than the Internet. How has that held up?} Not very well. It's so easy to make predictions. Brain imaging has been very valuable in medicine, but I don't know of any great breakthroughs that have resulted. So much of it traces only blood flow. You bring up a certain subject to someone who's got the skull cap on and a certain part of the brain lights up, and you want to conclude that's where that subject is handled in the brain. But that's reading shadows on the wall. No, it hasn't done all those wonderful things. But eventually, in the hands of rational people, it will have tremendous promise. That's science, not literature.

Interview by Jascha Hoffman, a writer based in New York.

e-mail: jascha@jaschahoffman.com

Tom Wolfe's fourth novel is due out later this year. Brainwave events run until 23 April at the Rubin Museum of Art, New York. 